By NAT WHITTEN

\title{
Audio-Visual Services at Lycoming College
}

Mr. Whitten is librarian and director, audio-visual education, Lycoming College.

Chancellor Robert M. Hutchins of the University of Chicago has said, "The film has the power that no other medium can command ... and can do more than any other single thing to unite the world." ${ }^{H}$ ad Dr. Hutchins said film and sound, he would have been more nearly correct, for the two move hand in hand into a position within the educational process.

The world events of the past decade have caused many people to see and hear much which had previously been beyond imagination. Much of this has been by actual experience, a great deal more vicariously. More than ever we, adults and students, have become used to learning through seeing graphic representations or hearing significant sounds. These experiences have become so vast and important that it would be difficult, even impossible, to revert to a total reliance upon the printed page which will not give up, but will share its potentialities with the various graphic arts and sound techniques. Unless educational systems realize this fact and make audiovisual methods a positive reality within their organizations, they will be in danger of not only being out-of-date, but will deny our younger generation a full education which is essential now, more than ever, to

1 From a talk by Chancellor Hutchins at a meeting of the National Association of Visual Education Dealers, Aug. 5, 1947. make the world safe for men and women.

It is with this total pattern in view that Lycoming College, along with many other schools and colleges in the country, has undertaken to incorporate within its program the best methods of instruction which have been and will be to a greater extent augmented with pictorial representations, recorded talks, speeches, and music, as well as direct experiences and observations.

\section{Library Serves as Depository}

The library has assumed this responsibility with the idea that students and faculty require information about various fields of interest and that such information must be supplied whether it be through the printed page, pictorial representations, or sound. The library, in this respect, will not only be a depository for these various sorts of materials, but through its staff will afford suggestions and will be a place for advisory service so that the audio-visual methods will be used by the faculty with maximum efficiency and capacity.

Our plan considers the college curriculum as being more than classroom activity and concerns itself with the total mental and physical development of students. Therefore, the audio-visual program, as such, does not recognize the extra-curricular, but must be concerned with all the activities which touch the lives of our students. The faculty and staff act as interpreters.

Following is given an outline of the 
audio-visual program discussing the mechanical devices used, the methods of organization, and some of the purposes which are considered important for immediate use and for future development.

Specifically for the purpose of instruction, the new academic building is provided with a large room which will seat sixty persons comfortably. Classes will be scheduled in this room for special sessions to look at moving pictures and hear records which are selected to enrich the particular subjects being studied. This room, though not complete, will eventually be equipped with the best of modern lighting and sound devices. In addition to this room, other class rooms and assembly places will be used as the particular cases demand. The physical equipment which has already been bought and planned for this school year is only a beginning of what is expected when the program has become fully developed.

\section{Film Equipment}

For moving pictures, there has been obtained a $16 \mathrm{~mm}$. projector with many features, including silent and sound controls, a stopping device for seeing a single picture for a longer time than is possible when the film is moving, and a public address attachment which will be used in some of the larger assemblies. Pictures will be shown to class room groups, assemblies of the students, and at certain exercises to which the public will be invited. Pictures made on the campus are to be shown. (One football game has been photographed and shown to the team for studying faults and possibilities as had been represented by the actual game.) Pictures rented from the various educational film agencies, and bought for the film library will also be shown. Only film with more than ephemeral value will be bought.

Included in the visual equipment will be a combination slide and filmstrip projector which, in most cases, is to be used in direct class room experiences. Filmstrips and slides are available on many subjects and include pictures which can be projected quickly and easily to present graphically what the instructor is attempting to teach. This device can be used in the middle of a classroom discussion or wherever the occasion arises. It has proved to be an excellent way to increase the understanding about certain objects and ideas which are difficult when only a verbal description is available. Though this projector can be used successfully in all subjects, it lends itself particularly to scientific materials. The library also keeps files of many flat pictures, both mounted and unmounted, which can supplement the other visual aids.

\section{Wire Recorder}

The wire recorder is one of the newest and most effective devices in the sound field. With the wire, phonograph, and radio combination, it is possible to record the spoken word or music onto the wire through a microphone arrangement, or directly from the radio or phonograph to the wire. The wire may be replayed as frequently as desired or demagnetized and reused an indefinite number of times. Each spool of wire will run continuously a little over an hour. The wire recorder can be used for a number of purposes. The language and speech departments will record the voices of students at various times throughout the year, these recordings to be used to study the development of language techniques. Any musical or spoken item may thus be recorded and saved to be played back whenever the occasion demands. This year we hope to use this machine for preserving some of the special events concerning the centennial celebration. 


\section{Record Library}

Three record players will be available, and though wire does supersede the record in many respects, the latter will be a large item in the program. The college owns a record library of many rare musical records, and is in the process of adding recent releases of musical recordings. One benefactor has presented the library with several records of considerable value. Represented in the record library will be examples of good speech, literature, and historical speeches which have been made by persons who are involved in the major world issues.

In connection with the record library, there will be many occasions when students and faculty may listen together to the great artists who have recorded the best in musical literature. These gatherings are informal, the only requirement being an interest in good music. During the appropriate seasons, this group will come together to hear the broadcasts of the Metropolitan Opera and New York Philharmonic Symphony Orchestra.

The last item in the original program is the public address system which will be used in the gymnasium, chapel, athletic field, and other places where there are large assemblies. This outfit consists of two indcor speakers, two outdoor speakers, and a control box which carries both a microphone and a record changer. This equipment is to be used for athletic events, dances, assemblies, and other all-collegiate functions.

Our audio-visual program will be under constant examination, study, and evaluation and it is the intention of the college staff to develop its maximum values in the whole pattern of the educational process.

\section{University of Oregon's Audio-Visual Service}

\section{(Continued from page 307)}

zation of field trips designed to produce for the future historian both audio and visual records of Oregon industries, peoples, institutions, and folk arts and customs. A committee of faculty members representing the anthropology, history, business, music, and other departments, as well as the library, has been appointed by the president to plan and help execute field trips of this kind. Consideration is being given to such projects as the sampling of local church services, city council meetings, lumbering activities, and such cultural groups as the Basques in Eastern Oregon.

\section{Conclusion}

As stated earlier, whatever is unique about the University of Oregon's audio- visual department derives largely from the effort to correlate the acquisition, organization, and use of audio, visual, and printed resources under the administration of the university librarian. The effort is frankly experimental, and its success or failure should be significant not only to librarians but also to audio-visual specialists and university administrators. The faculty attitude, with very few exceptions, has been warm even when departmental equipment was being transferred to the custody of the library. The library staff has been cooperative and eager to learn. If the experiment succeeds, the practicability of a fully correlated audio-visual and book service on a university campus will have been demonstrated. 